\title{
Analysis of Limiting Measures of Three-phase Short-circuit Current of $500 k V$ Intensive Receiving-end Power Grid in the Early Stage of UHV Construction
}

\author{
Xiao Hang ZHANG ${ }^{1, a}$, Si Qing SHENG ${ }^{1}$, Fu Qiang $\mathrm{LI}^{2}$, Yu Ou HU ${ }^{2}$, Wen Chao ZHANG ${ }^{3}$ and Yan PAN ${ }^{3}$ \\ ${ }^{1}$ College of Electrical and Electronic Engineering, North China Electric Power University, Baoding, Hebei, China \\ ${ }^{2}$ North China Grid Company Limited, Beijing, China \\ ${ }^{3}$ NARI Group Corporation Beijing Monitoring Technology Center, Beijing, China
}

\begin{abstract}
This paper took the intensive receiving-end power grid as the research object and analysed the problems of three-phase short-circuit current over-limited of 500kV intensive power grid in the early stage of UHV construction. Firstly, this paper analysed the influence factors of the short-circuit current based on selfimpedance analysis model of two-port network theory and the equivalent model of UHV power grid. Then, the applicable current-limiting measures were put forward. Finally, this paper proposed one scheme to solve the problems of three-phase short-circuit current over-limited of $500 \mathrm{kV}$ buses in one practical receiving-end power grid and verified the feasibility of this scheme from three different aspects. Aiming at the over-limited influential factors, the applicable current-limiting measures can be taken as follows: separating the $500 \mathrm{kV}$ bus at UHV substation, lapping the lines outside the substation and decentralizing the power supplies. The proposed measures can effectively solve the problems of short-circuit current over-limited in the early stage of UHV construction and provide reference for other power grid.
\end{abstract}

\section{Introduction}

In order to realize the transformation of energy and power development mode and solve problems caused by the deterioration of the environment, the strong smart grid will accelerates the UHV construction and pays more attention to the coordinated development of power grids at different levels ${ }^{[1]}$. In order to ensure sufficient power supply reliability, the receiving-end power grid must be further strengthened and have more supporting power supply capacity. The electrical contact of different substations will become increasingly close and the receiving-end power grid will shows the features of substation-intensive and line-intensive. While promoting the power supply ability and the security and stability of power grid, the short-circuit current level of UHV substations and load-center substations grows rapidly, which brings security and stability risks to the power grid.Therefore, it is necessary to study the corresponding limiting measures to prevent the short-circuit current exceeding the standard.

Aiming at the problems of short-circuit current over-limited in the development of power grid, the scholars have made a deep research in the development of short-circuit current limiting schemes. Literatures [2-3] analysed the current-limiting measures from different aspects and showed their advantages and disadvantages, but this paper didn't use engineering examples to illustrate. Literature [4] proposed corresponding measures to solve the problems of short-circuit current over-limited of Pengcheng substation in Guangdong power grid and verified those measures from different aspects, which has certain guiding significance to the engineering practice, but this paper didn't touch on the UHV project. Literature [5] disclosed the short-circuit current over-limited mechanism of $500 \mathrm{kV}$ bus at Chang-sha UHV substation based on self-impedance analysis model of two-port network theory and compared the economic cost of different schemes, but those schemes only related to the installation of current limiting reactors. The short-circuit current over-limited influential factors would change with the period and structures of the grid. Therefore, the main factors should be the first to analyze for making the most effective current-limiting measures.

This paper focuses on the problems of three-phase short-circuit current over-limited of $500 \mathrm{kV}$ intensive receiving-end power grid in the early stage of UHV construction. Firstly, the main over-limited influential factors are analyzed by the self-impedance analysis model and equivalent calculation model. Then, the applicable current-limiting measures corresponding to different factors are put forward. Finally, the effectiveness of the above measures is verified by the example of solving the problems of short-circuit current over-limited of one actual power grid. The research route of this paper is reasonable, and the proposed measures are

\footnotetext{
a Xiao Hang ZHANG: zhangxiaohang206@163.com
} 
simple and effective, which can provide reference to other power grid for making the current-limiting schemes in the early stage of UHV construction.

\section{The analysis of three-phase short- circuit current over-limited influential factors}

\subsection{Over-limited influential factors}

According to the periodic characteristics of the growth of short-circuit current in the power system development, the short-circuit current level of power girds with the highest two voltage levels is the highest and the consequences of short-circuit current over-limited are the most serious ${ }^{[6]}$. This chapter establishes the equivalent two port network model of $1000 \mathrm{kV}$ and $500 \mathrm{kV}$ two voltage levels to analyse the main influential factors of three-phase short-circuit current of $500 \mathrm{kV}$ bus of receiving-end power grid, and the impedance and power source in the model is the contact of each part. The self-impedance analysis model of short-circuit point is shown in Figure 1.

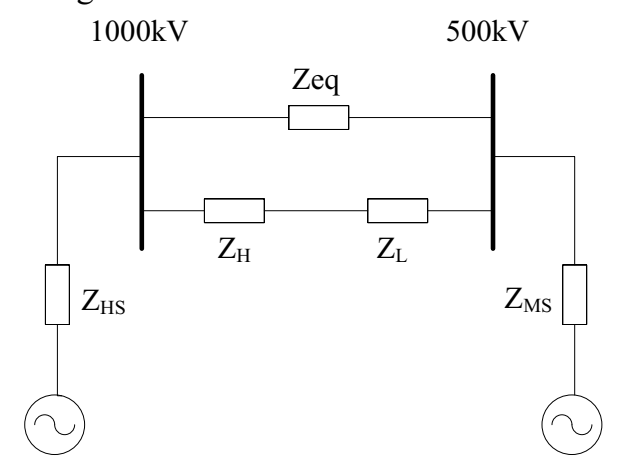

Figure 1. Positive sequence equivalent network of $500 \mathrm{kV}$ bus.

In Figure $1, Z_{\mathrm{HS}}$ is the equivalent impedance of UHV bus to the ground. $Z_{\text {eq }}$ is the equivalent contact impedance between the $1000 \mathrm{kV}$ power grid and the $500 \mathrm{kV}$ power grid. $Z_{\mathrm{H}}$ is the equivalent impedance of UHV transformer between the high voltage side and medium voltage side. $\mathrm{Z}_{\mathrm{L}}$ is the equivalent contact impedance between the UHV substation and the fault point. $Z_{M S}$ is the equivalent impedance of faulted bus of $500 \mathrm{kV}$ power grid to the ground.

From the above analysis model, the self-impedance of the $500 \mathrm{kV}$ short-circuit bus can be got in the formula (1).

$$
\begin{gathered}
Z_{K M}=\frac{Z_{T S} Z_{M S}}{Z_{T S}+Z_{M S}} \\
Z_{T S}=Z_{H S}+\frac{Z_{e q}\left(Z_{H}+Z_{L}\right)}{Z_{e q}+Z_{H}+Z_{L}}
\end{gathered}
$$

In the formula (1) (2), $\mathrm{Z}_{\mathrm{KM}}$ is the self-impedance of the $500 \mathrm{kV}$ short-circuit bus, $\mathrm{Z}_{\mathrm{TS}}$ is the transfer impedance of all the power supply on the UHV power grid to the fault point, and the smaller the value is, the greater the impact of the UHV on the fault point of $500 \mathrm{kV}$ power grid is.

In the early stage of UHV construction, the electrical distance between the UHV substations is relatively far. So, the value of $Z_{\text {eq }}$ is relatively large, which shows that the UHV injects the short-circuit current to the $500 \mathrm{kV}$ power grid mainly though the UHV transformers. The more close the electrical distance from the UHV substation to the fault site is, the smaller the value of $Z_{\mathrm{L}}$ is, and the greater the impact of the UHV on the fault point is. In the intensive receiving-end power grid, $\mathrm{Z}_{\mathrm{MS}}$ is the transfer impedance of all the power supply to the fault point in $500 \mathrm{kV}$ power grid, whose value is determined by the network density and the power supply quantity of the $500 \mathrm{kV}$ power grid. When the number of the substation tie-line and the power supply is large, the value of the $\mathrm{Z}_{\mathrm{MS}}$ would be small and the short-circuit current level of the fault point would be high. Therefore, the three-phase short-circuit current level of the $500 \mathrm{kV}$ buses of UHV and its surrounding substations, load-centre substations and the power-concentrated area substations would be significantly higher than other $500 \mathrm{kV}$ buses. So, the three-phase short-circuit current over-limited influential factors of $500 \mathrm{kV}$ buses in the intensive receiving-end power grid can be summarized as follows: UHV construction, too much tie-lines in the load-centre substation and power-concentrated construction.

\subsection{Influence of UHV power grid on the short- circuit current of $500 \mathrm{kV}$ receiving-end power grid}

In the study of effect of UHV power grid on the threephase short-circuit current of the $500 \mathrm{kV}$ power grid, the UHV power grid can be equivalent to a power supply which injects the short-circuit current to the $500 \mathrm{kV}$ power grid by the UHV transformers. The simplified system model is shown in the Figure 2.

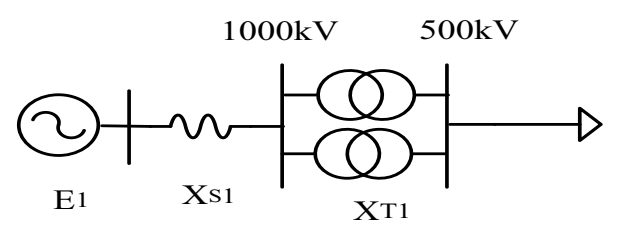

Figure 2. Simplified system model

When the three-phase short-circuit fault occurs in the $500 \mathrm{kV}$ bus, the short-circuit current of the fault point can be expressed in the formula (3).

$$
I_{500}=\frac{1}{X_{S 1}+X_{T 1}}
$$

Where,

$$
\begin{gathered}
X_{S 1}=\frac{S_{B}}{\sqrt{3} \cdot I_{1000} \cdot U_{B}} \\
X_{T 1}=U_{k 1} \% \times \frac{S_{B}}{n S_{N 1}}
\end{gathered}
$$


In the formula (3) $\sim(5), I_{500}$ is the short-circuit current of $500 \mathrm{kV}$ bus, $E_{1}$ is the power electromotive force, $X_{s l}$ is the equivalent impedance of UHV power grid, $X_{T 1}$ is the equivalent impedance of UHV transformers, $I_{1000}$ is the short-circuit current of $1000 \mathrm{kV}$ bus, $S_{B}$ is the reference system capacity, $U_{B}$ is the reference system voltage, $S_{N}$ is the rated transformer capacity, $U_{k l} \%$ is the transformer short-circuit voltage percentage, $n$ is the number of the parallel UHV transformers.

The formula $(4) \sim(5)$ show that, the change of $I_{1000}$ and $n$ would affect the value of short-circuit current of $500 \mathrm{kV}$ power grid. The value of $I_{500}$ can be obtained under different $I_{1000}$ and $n$ by the formula (3) (5), when $S_{B}=100 \mathrm{MVA}, \quad U_{k l} \%=0.21$ and $S_{N I}=3000 \mathrm{MVA}$. The results are shown in figure 3.

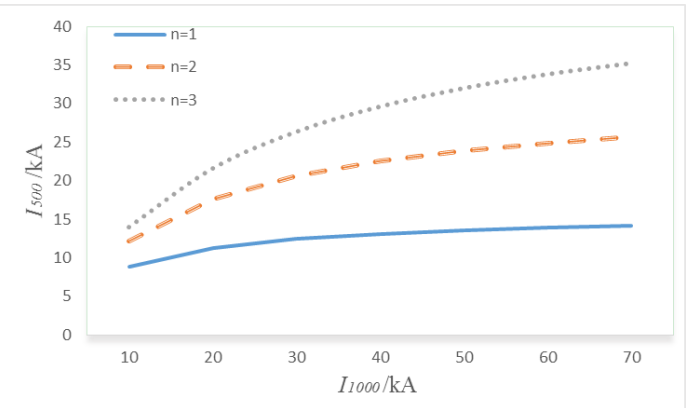

Figure 3. Three-phase short-circuit current of $500 \mathrm{kV}$ power grid

The Figure 3 shows that the UHV construction will have a great impact on the short-circuit current of $500 \mathrm{kV}$ power grid. When the short-circuit current level of UHV power grid reaches $30 \mathrm{kA}$, the short-circuit current of $500 \mathrm{kV}$ power grid which is provided by UHV power grid will exceed 10kA, and it will be greater when the number of parallel UHV transformers increases. So, the reasonable arrangement of UHV transformer units will have great effect on limiting the short-circuit current level of $500 \mathrm{kV}$ power grid.

\section{The short-circuit current limiting measures}

The current-limiting measures based on the different mechanism have obvious advantages and disadvantages and have different scope of application. Under the specific structure of power grid and over-limited influential factors, the selection of the current-limiting measures with good applicability will be the best ${ }^{[7]}$. In view of the above three-phase short-circuit current over-limited influential factors, this chapter analyses the applicable and corresponding current-limiting measures.

\subsection{Separated operation of $500 \mathrm{kV}$ bus at UHV substation}

In the early stage of UHV construction, the UHV grid structure is relatively weak and the $500 \mathrm{kV}$ power grid does not have the ability for the partition. Therefore, other measures should be taken to control the short-circuit current level. The separated operation of $500 \mathrm{kV}$ bus at UHV substation is the available current-limiting measures. The way of the separated operation of $500 \mathrm{kV}$ bus at UHV substation is an economical and effective method to suppress the influence of UHV power grid on the short-circuit current of the $500 \mathrm{kV}$ power grid. This measure can greatly reduce the short-circuit current of the substation with the breakdown bus and can be operated easily. But to a certain extent, it reduces the power supply reliability of the substation and may cause the uneven distribution of the bus load ${ }^{[8-10]}$

After the separated operation of $500 \mathrm{kV}$ bus at UHV substation, the short-circuit current limiting effect of the substation in the near of the UHV substation will be influenced by the $500 \mathrm{kV}$ grid structure outside UHV station. The way of influence can be divided into two cases, one is that there is the loop network outside the UHV station (small loop) and the other is no loop network (large loop). Figure 4 and Figure 5 are schematic diagrams of the separated operation of $500 \mathrm{kV}$ bus at UHV substation under two cases.

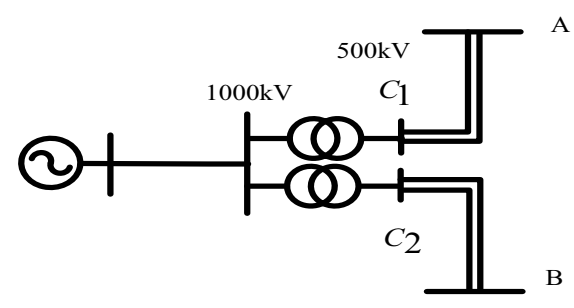

Figure 4. No loop network outside the UHV station.

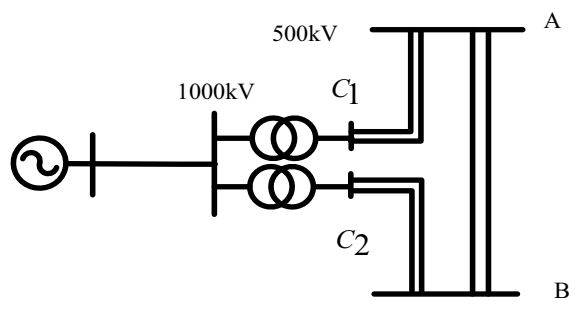

Figure 5. With loop network outside the UHV station.

Figure 4 shows that there is no $500 \mathrm{kV}$ loop network or there is a large $500 \mathrm{kV}$ loop network outside the UHV substation. The separated operation of $500 \mathrm{kV}$ bus at UHV substation will obviously increases the self-impedance value of the A node and B node to reduce the short-circuit current. From Figure 5 we can see that there is a small loop network outside the UHV substation. When the short-circuit fault occurs in the A node, the UHV power grid can inject the short-circuit current both by the transformer connected with the A node and the small loop after the separated operation of $500 \mathrm{kV}$ bus at UHV substation. The short-circuit current of the loop is mainly determined by the impedance of the loop network. Under the situation that the electrical distance of the loop network is short, the current-limiting effect of separated operation of $500 \mathrm{kV}$ bus for A substation is poor. 


\subsection{Lines out series or lapping outside the substation}

At present, the transmission lines in the substation are generally $3 / 2$ connection mode. In this mode, the lines in series can be connected only through the intermediate switch by turning off the switches on both sides. Thus, the transmission lines will don't connect to the substation, which can decrease the number of tie-lines in the load-centre substation and increase the self-impedance of bus to reduce the short-circuit current level. The schematic diagram of this measure is shown in Figure 6.

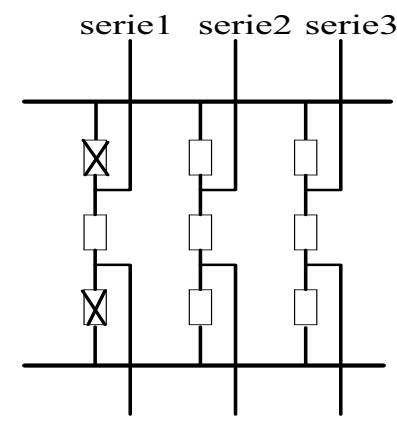

Figure 6. Schematic diagram of lines out series

Using $3 / 2$ connection mode in substation to achieve the operation of line out series or lapping the lines outside the substation is one of the effective measures to restrain the excessive short-circuit current. The reliability of the power flow can be taken into account by the means of line out series or lapping lines outside the substation to reduce short-circuit current, but external electrical connection and the stable level of the substation are weakened. Therefore, it is recommended that the circuit breaker which are used for the line out series or lapping outside the substation should be in a hot standby state in order to be closed in time when the fault occurs, which can avoid serious accidents.

\subsection{Decentralizing the power supplies}

When the power supplies are connected to a certain area in clustering way, the short-circuit current level of the area is greatly increased. The greater the power density in the area is, the more serious the problem of short-circuit current over-limited is. In the beginning of power supply construction, the power supplies should be decentralized and connected to different trunk transmission lines based on the direction and scope of power transmission to make the network has better adaptability. Under the condition that the system reliability is not weakened, pulling open the electrical distance of power grid can both reduce the short-circuit current level and be prepared for the partition operation of $500 \mathrm{kV}$ power grid. The influence coefficient of the short-circuit current of power supply would vary with the power access point ${ }^{[11]}$. Therefore, in the beginning of power supply construction, the power access points should be chosen reasonably. Designers also should give full consideration to the influence of the power supply on the short-circuit current and reserve a certain space to the development of power grid.

\section{Example analysis}

\subsection{The phenomenon of three-phase short- circuit current over-limited of $500 \mathrm{kV}$ buses in TQ power grid}

TQ power grid is a typical urban receiving-end power grid with double loop network structure and is located at the intersection of two $1000 \mathrm{kV}$ UHV AC transmission channels. The schematic diagram of the TQ power grid structure is shown in Figure 7. The average electrical distance of adjacent substation of TQ power grid is only $15 \mathrm{~km}$ and the power supplies of $500 \mathrm{kV}$ power grid are connected to the TQ eastern power grid in clustering way. TQ power grid shows obvious features of substation-intensive and line-intensive and the three-phase short-circuit current level is relatively high. Based on the operation planning data of TQ power grid in 2018, the three-phase short-circuit current of $500 \mathrm{kV}$ buses is calculated by the power system analysis software PSD-BPA, and the short-circuit current level of substations whose short-circuit current excess the standard is shown in Table 1.

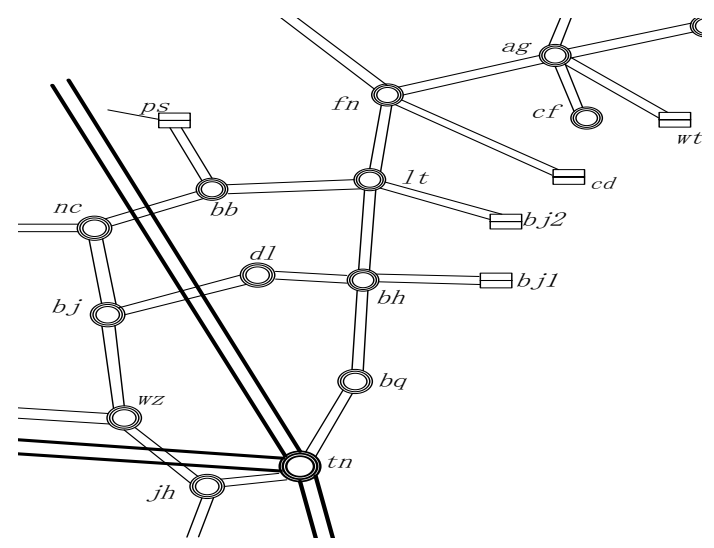

Figure 7. The structure of $500 \mathrm{kV}$ TQ power grid.

Table 1. Calculation results of three-phase short-circuit current of $500 \mathrm{kV}$ buses in TQ power grid in 2018

\begin{tabular}{|c|c|c|c|}
\hline \multirow{2}{*}{ No. } & \multirow{2}{*}{ Bus } & $\begin{array}{c}\text { Breaking } \\
\text { current }\end{array}$ & $\begin{array}{c}\text { Short-circuit } \\
\text { current }\end{array}$ \\
\cline { 3 - 4 } & & $\mathrm{kA}$ & $\mathrm{kA}$ \\
\hline 1 & $l t$ & 63 & 75.053 \\
\hline 2 & $t n$ & 63 & 70.806 \\
\hline 3 & $j h$ & 63 & 69.386 \\
\hline 4 & $f n$ & 63 & 68.443 \\
\hline 5 & $b h$ & 63 & 63.948 \\
\hline
\end{tabular}

The Table 1 shows that the problems of three-phase short-circuit current over-limited of $500 \mathrm{kV}$ buses in TQ power grid are serious. The three-phase short-circuit current of $l$ substation has reached $75 \mathrm{kA}$, which is far more than the rated current $63 \mathrm{kA}$ of circuit breaker. Besides, the three-phase short-circuit current of $t n$ 
substation, $j h$ substation and the $f n$ substation is also high and all of them is more than $68 \mathrm{kA}$. The short-circuit current over-limited substations mainly distribute near the UHV substation or in the power-concentrated area, which shows that the short-circuit current of TQ power grid is greatly influenced by UHV construction and power-intensive construction. From the above analysis, we can know that the short-circuit current over-limited influential factors of TQ power grid are consistent with the proposed over-limited influential factors of the intensive receiving-end power grid.

\subsection{The schemes of current-limiting measures}

The UHV construction and the power-concentrated construction are the main influential factors for the problems of three-phase short-circuit current over-limited of $500 \mathrm{kV}$ buses in TQ power grid. According to the current-limiting measures corresponding to the short-circuit current over-limited influential factors of intensive receiving-end power grid, the current-limiting schemes can be made of two measures.

(1) Measure One: separated operation of $500 \mathrm{kV}$ bus at tn UHV substation. The $500 \mathrm{kV}$ bus at $t n$ UHV substation is separated into two parts, and one of them connects to $j h$ substation and the other one connects to the $b q$ substation. The schematic diagram of the structure is shown in Figure 8 .

(2) Measure Two: grafting cd power plant units from $f n$ substation to $c f$ substation, lapping the line $f n-l t-b b$ outside the $l t$ substation. The schematic diagram of the structure is shown in Figure 9.

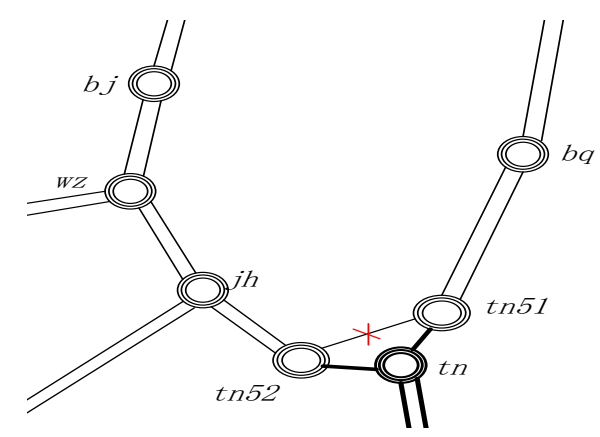

Figure 8. Measure One.

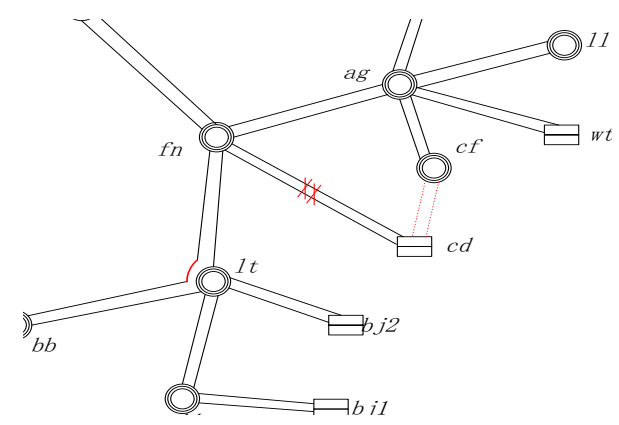

Figure 9. Measure two.

After taking the above measures, the three-phase short-circuit current level of $500 \mathrm{kV}$ buses in TQ power grid is shown in Table 2. Table 2 shows that the short-circuit current level of $500 \mathrm{kV}$ buses at different substations in TQ power grid decreases to less than the rated breaking current of circuit breaker. The short-circuit current of $t n$ substation and the $j h$ substation decreases more than $20 \mathrm{kA}$, which shows that separating the $500 \mathrm{kV}$ bus of UHV substation can greatly weaken the impact of UHV power grid on the three-phase short-circuit current of $500 \mathrm{kV}$ power grid. The power density and the network density of eastern region of TQ power grid has been reduced after taking the second measure and the short-circuit current level of $500 \mathrm{kV}$ bus of $l t$ substation, $f n$ substation and $b h$ substation decreases to less than the rated breaking current of circuit breaker.

Table 2. The three-phase short-circuit current of $500 \mathrm{kV}$ buses in TQ power grid after taking measures.

\begin{tabular}{|c|c|c|c|}
\hline \multirow{2}{*}{ Bus } & $\begin{array}{c}\text { Initial short- } \\
\text { circuit current }\end{array}$ & $\begin{array}{c}\text { Short-circuit } \\
\text { current after } \\
\text { taking } \\
\text { measures }\end{array}$ & $\begin{array}{c}\text { Change } \\
\text { in short- } \\
\text { circuit } \\
\text { current }\end{array}$ \\
\cline { 2 - 4 } & $\mathrm{kA}$ & $\mathrm{kA}$ & $\mathrm{kA}$ \\
\hline Lt(lap joint) & 72.16 & 38.280 & 33.88 \\
\hline$l t$ & 72.16 & 61.429 & 10.731 \\
\hline$t n 51$ & 70.764 & 34.751 & 36.013 \\
\hline$t n 52$ & 70.764 & 44.867 & 25.897 \\
\hline$j h$ & 69.335 & 48.806 & 20.529 \\
\hline$f n$ & 67.285 & 61.928 & 5.357 \\
\hline
\end{tabular}

From the point of view of power flow distribution, there is certain uneven power distribution among the two transformers of $t n$ UHV substation after taking the first measure. One of them is $1400 \mathrm{MW}$, the other one is $900 \mathrm{MW}$. But in the maintenance case of any one, the power of the other transformer is not overloaded. Besides, the power flow of TQ western power grid increases after taking the first measure. The single line power flow of $n c-b j$ transmission line increases to $1300 \mathrm{MW}$ and the maintenance mode should be arranged reasonably to prevent the overload. The cd power plant mainly provides the power to the $c f$ industrial zone after taking the second measure, which conforms the trend that the electricity consumption of $c f$ industrial zone increases year by year. Lapping the line $f n$-lt- $b b$ outside the $l t$ substation does not affect the power flow transfers from the north power grid to the TQ western power grid and the power flow is reasonable.

To analyse the scheme from the aspect of security and stability, the power flow of all the single transmission line is below $1800 \mathrm{MW}$ and is not overloaded whether in normal operation mode or in maintenance mode after taking the measures, except the $n c$-bj transmission lines. The power flow of single $n c-b j$ transmission line would reaches to $2300 \mathrm{MW}$, which is a heavy load but not overloaded, when one of the two lines is broken. When the $\mathrm{N}-2$ fault happens in the $a g$ side of the $c f-a g$ transmission lines, there is a need to shut down one unit in the cd power plant to maintain the stability of the system. When the N-2 fault happens in other transmission lines, the system can always keep the stable operation.

Seen from the above analysis, the problems of three-phase short-circuit current over-limited of $500 \mathrm{kV}$ buses in TQ power grid can be effectively solved. 
Besides, the power flow distribution is reasonable and the power grid can ensure the safe and stable operation. Therefore, the proposed scheme can be used as a feasible solution to solve the problems of three-phase short-circuit current over-limited of $500 \mathrm{kV}$ buses in TQ power grid. This example shows that the phenomenon of three-phase short-circuit current over-limited of $500 \mathrm{kV}$ intensive receiving-end power grid will occur in the early stage of UHV construction, and short-circuit current over-limited problems of the substations near the UHV substation or in the power-intensive area will be more serious. The measure of separating the $500 \mathrm{kV}$ bus at UHV substation can effectively suppress the effect of UHV on the short-circuit current of $500 \mathrm{kV}$ power grid. Grafting the power plant units and lapping the lines outside the substation can effectively decrease the power density and the network structure density of power-intensive area to reduce the short-circuit current level.

\section{Conclusions}

In the early stage of UHV construction, the problems of three-phase short-circuit current over-limited of $500 \mathrm{kV}$ intensive power grid will be serious. The three-phase short-circuit current over-limited influential factors can be summarized as follows: UHV construction, too much tie-lines in the load-centre substation and power-concentrated construction. Aiming at these over-limited influential factors, the applicable current-limiting measures can be taken as follows: separating the $500 \mathrm{kV}$ bus at UHV substation, lapping the lines outside the substation and decentralizing the power supplies. The example of solving the problems of three-phase short-circuit current over-limited of TQ receiving-end power grid shows that the research route of this paper is reasonable, and the proposed measures are simple and effective, which can provide reference to other power grid for making the current-limiting schemes in the early stage of UHV construction.

\section{References}

[1] F. Han, F.L. Song, J.S. Luo, \& L. Chang. Research on development of transmission power grid in 13 (th) five-year period. Electric Power. 48(1): 11-14 (2015).

[2] Q.T. Ruan. Present situation of short circuit current control in shanghai power grid and countermeasures. Power System Technology. 29 (2): 78-83 (2005).

[3] G. Han, L. Han, \& L. Wu. Application and development of methods on limiting power grid's short-circuit current. Power System Protection \& Control. 38(1): 141-144(2010).

[4] X.P. Yang, L. Li, Y.X. LI, etal. Running programs of limiting $500 \mathrm{kV}$ short-circuit current in Guangdong power grid. Automation of Electric Power System. 33 (7): 104-107 (2009).

[5] G.D. Liao, X.T. Xie, Y.L. Hou, etal. Analysis on the Problems of Three-phase Short-circuit Current Overlimited of $500 \mathrm{kV}$ Bus When UHV Connected to Hunan Power Grid. High Voltage Engineering.
41(3):747-753 (2015).

[6] F. Wang, \& Q.J. Li. Short-circuit current control for beijing-tianjin-tangshan grid. North China Electric Power. 4: 17-19 (2007).

[7] Q.Z. Sun, Z.X. Cai, A.M. Li, etal. A short-circuit current over-limited mechanism of $500 \mathrm{kV}$ power system and the adaptability of limiting measures. Automation of Electric Power Systems. 33(21), 92-96 (2009).

[8] T. Luo, L.X. Liu, K. Wang, etal. The influence of UHV accesses to Tianjin $500 \mathrm{kV}$ power grid on the short-circuit current and the limiting measures. Electric Power Construction. 36(8): 79-83 (2015).

[9] J. Yuan, W.Y. Liu, M.Q. Dong, etal. Application of measures limiting short circuit currents in northwest china power grid. Power System Technology. 31(10):42-45 (2007).

[10] H.Y. Ma. Research on method of limiting shortcircuit current and partition principle for UHV interconnected power system. North China Electric Power University. pp: 21-24 (2014).

[11] J. Zhou, D. Jin, W.Z. Wang, etal. Analysis of influence of huge power supplies grid-connection modes on short-circuit current. Advanced Technology of Electrical Engineering and Energy. 31(1): 48-51 (2012). 